The Geographical Journal of Nepal

Vol. 15: 119-130, 2022

DOI: https://doi.org/10.3126/gjn.v15i01.42890

Central Department of Geography,

Tribhuvan University, Kathmandu, Nepal

\title{
Indigenous knowledge and local practices for disaster risk reduction: A study of Kailali district
}

\author{
Narayan Prasad Timilsena ${ }^{1^{*}}$, Krishna Maya Devkota ${ }^{2}$
}

${ }^{1}$ Central Department of Education, Tribhuvan University

${ }^{2}$ Mahendra Ratna Campus, Tahachal, Tribhuvan University

*Corresponding author: narayan12.timilsena@gmail.com

Received: 03 October, 2021; Accepted: 20 October, 2021; Published: March, 2022

\begin{abstract}
Disasters which are resulted due to the natural or anthropogenic environmental damage processes such as deforestation, desertification, loss of biodiversity, soil erosion etc. and are increasing day by day. As such there are potentialities for outbreaks and their high risk at any places at any time. There are many literatures which suggest the possibility of disaster risk reduction and early warning through local indigenous knowledge and practices. The present study is an attempt to explore, evaluate and analyse the local knowledge and skills that are being practiced and used to reduce the risk of various types of natural hazards. Kailali district lying in the Sudur Paschim Province of Nepal is chosen as the study area. Chure rural municipality lying within Hill areas and Tikapur urban municipality lying within Terai plain areas of the district were selected as the research sites to evaluate the landslide and flood related local indigenous knowledge and practices respectively. Using a multi-assessment methodology of collecting information through targeted group discussions, key informant interviews, household surveys, and field observation methods, an attempt has been made to analyse the data to explore indigenous local knowledge, skills, and traditional practices related to disaster risk and mitigation in the study area. The indigenous knowledge, skills and practices on disaster risk reduction and early warning system have been developed by generations and tested in the absence of the scientific developments. However, many communities have lost their local knowledge, skills, and traditional practices because of non transfer by the senior citizens to the young generations. The findings of the study indicate that indigenous and local knowledge and practices are valuable resources that can support in the process of disaster management, prevention, preparedness, and cost-effective disaster risk reduction. Therefore, the researchers view that it would be wise decision
\end{abstract}


focusing the policy framework by integrating indigenous and local knowledge, wisdom, and skills of the local people.

Keywords: Indigenous knowledge, local practices, disaster risk, risk reduction

\section{Introduction}

Locally and culturally in a context-specific, collective, holistic, and adaptive knowledge is referred to indigenous knowledge (IK). However, IK was previously largely shadowed in the field of development and conservation (Mistry, 2009). Indigenous knowledge is currently living as a revival and it is necessary to include the knowledge in every developmental and conservation activities concerned to the people. The indigenous knowledge for disaster risk reduction is also important for the disaster-prone area (Risk Nexus, 2015). Natural disasters are sudden and unimaginable. Within moments of the onset of the disaster, human settlements, and infrastructures such as power dams, poles, bridges, security stations, community buildings, arable land, and invaluable human life can be destroyed in an instant (Mishra, 2009). Now-a-days, the human-made disasters are also appearing due to development infrastructures being built without appropriate planning (Bhandari et. al., 2020). Various studies have shown that floods and landslides displace thousands of homes and kill hundreds of people every year (MoHA, 2013; Poshan, Sharma, Marshak, \& Stites, 2013). In Nepal, it is the common fact that there is a risk of landslides in the hilly areas and floods in the Tarai region. Kailali district is not an exception to it.

Kailali district covers both hilly areas and Tarai plain areas and affected commonly by both the floods and landslide hazards. The district is one of the severely affected areas by hazards in Nepal (Acharya, 2012). Due to the physiography of the Chure area of the Kailali district, there is a high risk of landslides (Pokhrel, Chidi, Timilsena, \& Mahat, 2021). The study carried out by Tuladhar, Yatabe, Dahal, and Bhandary (2015) outlined several places (Kimtola Khasare of Chure rural municipality, Simal village of Gundi river and Khanidanda etc.) within the Chure hill region as the landslide affected areas.

Similarly, the Karnali River loaded with the sediments from the Himalayan and Hilly regions release the sediments in the plain areas due to decrease in slope. It produces erosion, inundation, and flooding problems in the Terai region every year. The same study carried out by Tuladhar, Yatabe, Dahal, and Bhandary (2015) identified the settlements along the river Karnali from Daulat Ghat, Karmi Danda, Saipur, and Sati to Dhansinghpur in the Tarai are at high risk of floods. Acharya (2017) discuused on other types of disasters such as drought, lightning, and cold wave which are also affecting the 
people, farmland, and plants of Kailali district from time to time. Various efforts have been made to reduce the risk of outbreaks from landslides and flood hazards(Gautam \& Khanal, 2009). There have been many governmental, non-governmental and local efforts to reduce the risk of floods and landslides. Among them are tree planting, improvement of farming system, temporary and permanent embankments, measures to reduce floods and landslides. Despite this, many settlements in the Chure region are at risk of landslides, and settlements in the Tarai are at high risk of floods (MoSTE, 2015). Almost 25 houses of Chure rural municipality have been displaced and are living temporarily in Chaumala of Kailali (Field survey, 2021). Similarly, most of the residents of Daulat Ghat in plain area are always in worry about the future floods and are ready to transfer of their settlements if it is provided by the government.

Occurrence of many types of disasters are common in Kailali district and multiple impacts have been seen in the community (Oven et al., 2017). In such a situation, it is necessary to take appropriate initiatives to reduce the risk of disasters for the local people (Pokhrel, et al., 2021). In this context, the present study aims to highlight the indigenous knowledge, skills used and practices adopted by local people to avoid and mitigate the risk of natural disasters in the area.

\section{The study area}

Kailali district lying within the Tarai ecological region of Sudur Paschim Province of Nepal is selected as the study area for the present research issue. The district has an area of 3,235 Sq. Km. and a population of 775,709 (CBS, 2011). There are 13 local units including one sub-metropolitan, six urban municipalities, and six rural municipalities. Among them, Chure rural municipality and Tikapur urban municipality of the district were selected as the research sites for this study (Figure 1). 


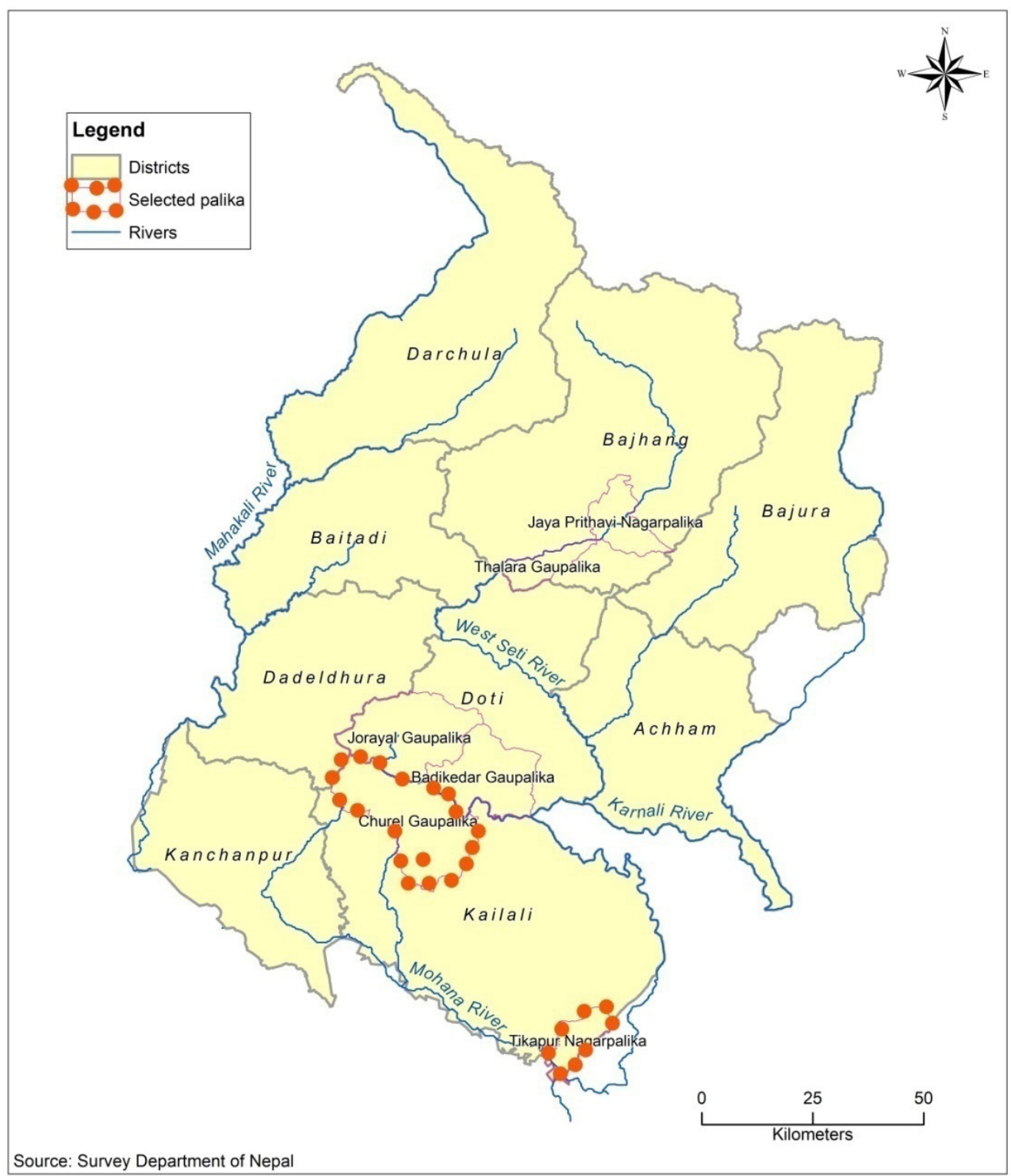

Figure 1: Location of the research sites within Sudur Paschim Province

\section{Materials and methods}

The study has used both the primary and secondary data. Available and relevant secondary data have been used. Google images were used to identify hazard prone areas 
and Geographical Information System (GIS) based maps were used during the field observation phase. Multi-stakeholders were included in the preliminary data collection for information on local indigenous knowledge and local practices for disaster risk. Outbreaks, risks, hazards, local resources, and values were identified by impact groups. Plans were drawn up for a key informant interview (KII), and a target group discussion (TGD). Target group discussion (TGD) was used to evalute natural hazards and management of local values, risk mitigation, and available resources at the local level.

Key informant interview (KII) was conducted to explore the environment and the severity of natural disasters, causes, and special hazards in the local population. The TGD method was used with the presence of group leader at the meeting with the participants to discuss and present a common basis for identifying and prioritizing disaster risk reduction (DRR) issues in the Karnali River and Thuli Gadh Reservoir. It was used to identify local indigenous practices for the benefit of knowledge, skills, experiences, and support through partnerships with local communities, agencies, and organizations. In the same way, a total of 180 households (HHs) were selected and surveyed through field study. For disaster risk reduction (DRR) public activities and awarness, satellite images were used in the selected locations to promote local knowledge. Discussing with local representatives and participants, specific issues, challenges, and related local knowledge skills and practices to identify natural disasters and the risks created by them were identified as essential local knowledge and skills.

\section{Results and discussion}

The present section contains the information obtained from targeted group discussions, key informant interviews, household surveys, and field observation methods and discussions based on the data to explore indigenous local knowledge, skills, and traditional practices related to disaster riskreduction and mitigation.

\section{Local indigenous knowledge for disaster risk reduction}

The indigenous knowledge, skills, and local practices for disaster risk reduction were explored based on uchoghar made by both concrete and wood, instant bag preparation, plantation, an early warning system for disaster risk, dam construction, planting cactus on the roof of a house, and indigenous knowledge for weather forecasting.

\section{High-rise house (uchoghar): An indigenous knowledge to reduce the risk of inundation}

During the surveying of households in Sati Bazaar in the Kailali district, suddenly our eyes went to the concrete house built five feet above the ground. In the middle of the 
house, there was a staircase leading to the ground from both sides. We were amazed that we had never seen such a house before. An old man was sitting on the stairs, we had some formal talk and the old man illustrated on the High-rise house:

My name is Man Bahadur. We have moved here from Chamunda of Dailekh district. My sons have gone abroad. The floods here are very painful. The house was built by his son with money from abroad to protect him from the floods. In the local language, it is called Uchoghar (informal talk, 15 April 2021).

Photograph 1 and 2 show such houses in Kailali district used as the local indigenous knowledge and practices for the risk reduction of the flood. Three hours before the floods due to the water level rising above the danger limit at Karnali Chisapani area Sirens that have been installed in many flood-hit areas used to inform about the potential flood hazard to the area. Houses built with a base five feet above the ground level 'uchoghar' are being used to protect themselves from floods. As soon as the signal is received, children, old age people, and pregnant women are rescued and taken to uchoghar (highrise community buildings) and personal high-rise buildings. Dube and Munsaka (2018) also discussed on such indigenous knowledge (IK).
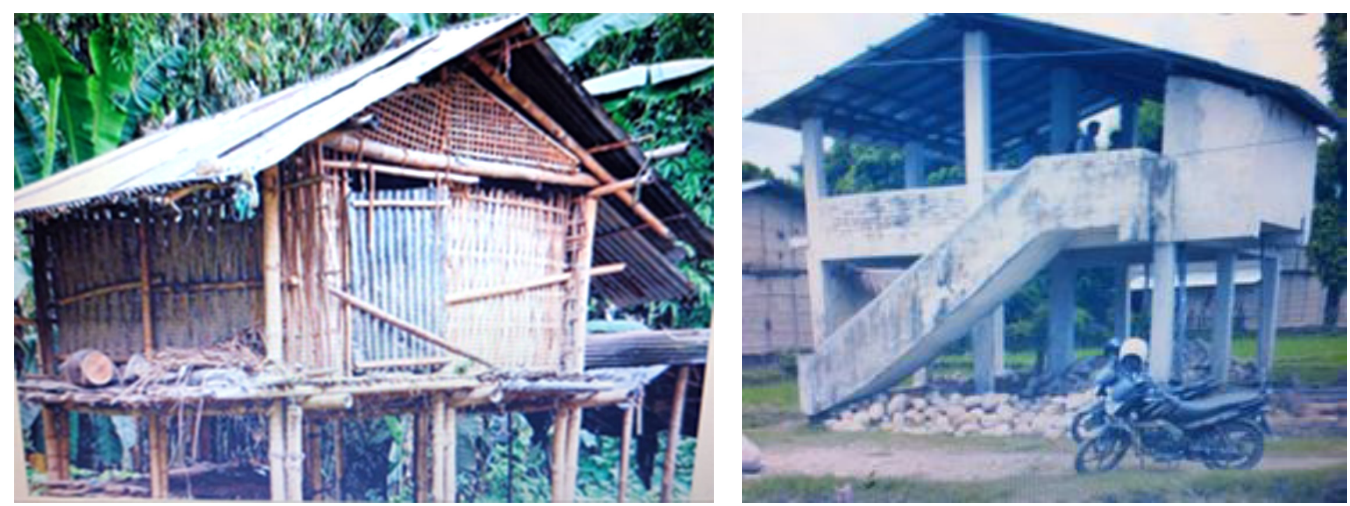

Photograph 1 and 2: Traditional uchoghar (high house) for the risk reduction of inundation

\section{Instant bag: An indigenous knowledge to reduce flood risk}

During the on-site survey in the settlement of Daulatghat Heights which see floods each year the importance of instant bag was described as follows:

I am Bikshu Chaudhary, a resident of Daulatghat Heights. The Karnali river floods are causing loss of wealth every year. How do you know if a 
flood is coming and what can you do to reduce your risk? To the question, he said that three hours before the flood came, news came from Karnali Chisapani and the siren starts ringing. We pack the important ingredients and the food that will last for a few days and put them in the bins with prepreparation. As soon as we see a sign of a flood, we rush to safe place. It would have been better if the government had relocated us to a safer place (interview recorded 16 April 2021).

As per the information the instant bag contains the important materials such as citizenship, educational certificate, 'Lalpurja' (land title deed), medicine and packed food as the roasted edible maize; soybean, wheat, etc. for two to three days. The bag is made ready as a pre-preparation and is 'balo ma badhne' (tied to the roof of the house). All family members with the emergency bag are requested to move to a safer place immediately after receiving the flood signal. Similar technique was carried out by UNEP (2008) for preparedness for disaster risk reduction in Africa.

\section{Plantation: An indigenous knowledge of reducing landslide and drought risk}

The plantation method has been found during the survey at the Kimtola Khsare, Guni Khola, and Simalgaun settlements which were landslide prone areas. The place witnessed the damage of cultivated area, houses and even the loss of lives. The causes of landslides could be natural or human- made (Photograph 3 and 4). One of the local narrates the situation as follows:

Chakra Bam, a resident of Kimtola Khasare told sadly that the landslide of the Thuligadh side is causing damage of cultivated area every year. What do you do to reduce landslide risk at your area? To the question, he said that they are persuing local indigenous knowledge to reduce the risk of landslides like planting of siru, babiyo, simali, badi, and ram bans. Similarly, they plant bans, uttis, lampate, and kholipeepal to protect the source of water and reduce the risk of drought (TGD, 18 April 2021).

Using the roots of the plants like Rambans, Siru, Babio, Simali, and Badi to reduce the risk of landslides has been approved by the scientific experiments also because the plants can grow easily anywhere and have a high soil binding capacity. The local people of Kimtola Khasare area are using the same traditional practice by planting Rambans, Bamboo, Siru, Babio, Simali, and Badi for risk reduction of landslides in landslide prone areas. Similarly, to maintain the moisture or the source of water are preserved by planting trees like Bans, Uttis, KholiPeepal, and lampate in local areas. The roots of these plants 
absorb a lot of water and after some time return water to the soil from the roots. Thus the risk of drought can be reduced by practicing and using such traditional indigenous local knowledge. Acharya, Subedi and Shrestha, (2016) advocated for similar indigenous knowledge for the mitigation of climate change and adaption measures.
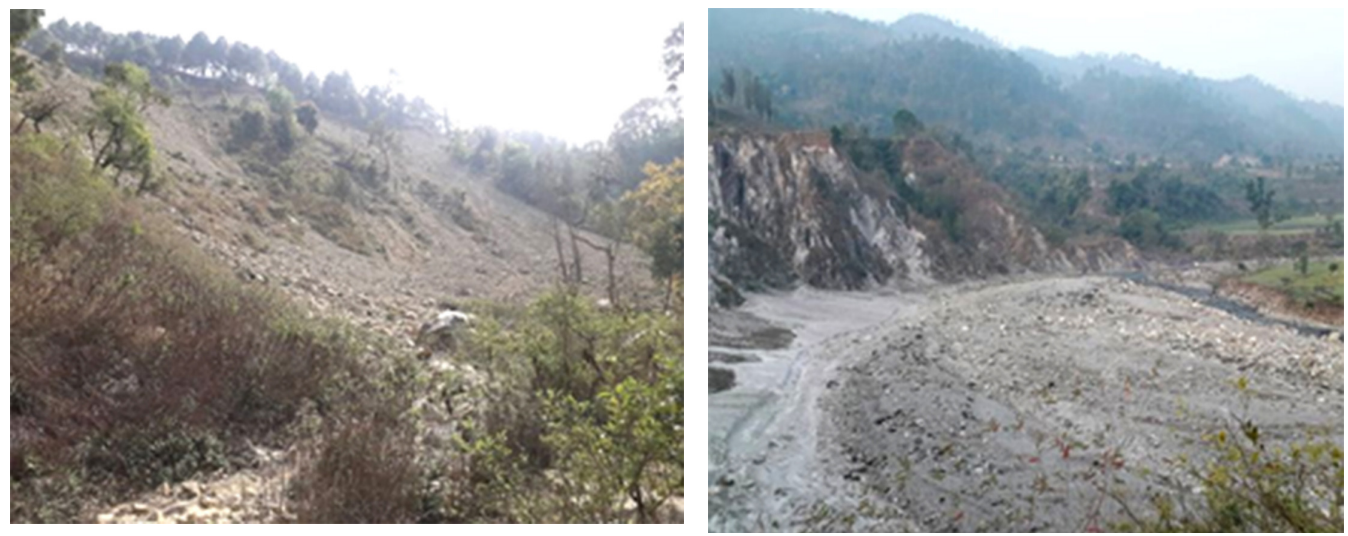

Photograph 3 and 4: Landslide of Sahajpur and Kimtola due to road construction and bank cutting of Thuligad

\section{Dam construction: A measure to reduce flood risk}

Settlements such as Karmi Danda and Saipur behind the Tikapur Park are located within the high risk of floods and siren-connected. During the field visit a local person narrated the importance of the dam to reduce flood risk in his own words as follows:

Initially, on the initiative of the locals, a temporary barrier was set up on the Karnali side by placing sand bags which reduced the risk of diverting the river. Based on the experiences recently a concrete embankments have been constructed at the initiative of the Government of Nepal, due to which the risk of floods has been reduced (KII, 2021).

The construction of a temporary barrier filled with sand and soil in plastic bags to prevent the river flowing into the settlement was observed during the field visit (Photograph 5). That was the indigenous local knowledge, practices, and skill of local people to reduce the risk of flood. In some parts of Karnali river bank, concrete barriers have also been erected with the initiative of the local and central governments to reduce flood inundation, erosion, and loss of cultivated land (Photograph 6). Lemperiere, (2017) advocated for dam construction as the measures for flood controls as well. 

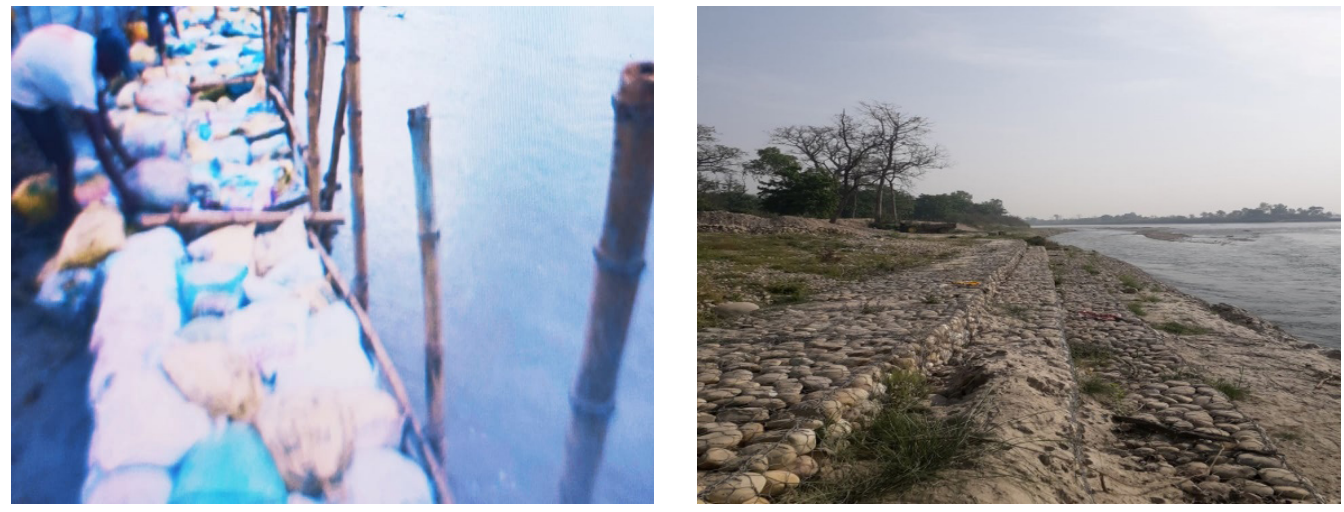

Photograph 5 and 6: Temporary and permanenet dam construction on Karnali river bank

\section{Indigenous local knowledge of early warning system for disaster risk reduction}

An indigenous local knowledge of the early warning system of an outbreak is known by only few people of the study area. Some senior citizens have the experiences to predict an outbreak. The results of the TGD on this issue is as follows:

Sudden onset of snakes, crabs, and frogs out of the stream and river as well as sudden changes in the behavior of domestic cows running backward could be predicted for the potential hazards. Ants also indicate heavy rainfall. To protect their eggs from heavy rains, all the members of the ant are seen carrying their eggs to a safe place. From such local knowledge it can easily be predicted for heavy rain (TGD, 2021).

The study of Sakic Trogrlic and Van Den Homberg (2018) explored the behavior changes of the celestial body as the early signs of an outbreak in Malawi. Scientifically black clouds, daytime storms and hurricanes are interpreted as the signs of floods, landslides, and heavy rain. Nowadays sirens have been installed in disaster-affected areas to protect them from the hazard of disasters. Previously, there were no such devices as such the people had to predict the early warning of the disasters from their own experience which was also justified in the study of SakicTarogarlic and Van DenHomberg (2018).

\section{Indigenous knowledge for weather forecasting}

Now-a-days, many modern devices have been made to forecast the weather. But there was no device to forecast the weather in ancient times. One of the informant in the study area says the clues of the indigenous knowledge of weather forecasting as follows. 
Weather can be predicted from the experience of roasted maize and soybeans that are taken by the farmers to take as snacks at work in the field. The moisturizing of roasted maize and soybeans hints for weather changes. In some cases the moist fallen leaves of the trees and the moisturizing feelings of bidi smokers could also be useful in this connection (KII, 2021).

Apart from the above experiences the local indigenous knowledge and practices the laziness feeling of human beings, moistering of roasted corn, and migration of ants were also used for weather forecasting. Okonya and Kroschel (2013) cocluded on such indigenous knowledge in weather forecasting in Uganda.

\section{Planting Siudi (cactus) on the roof of the house: An indigenous knowledge to reduce the risk of thunderstorm}

During this study, we visited the Kimtola settlement of Chure village in Kailali district. Cactus was found planted on the axis of every houses of the settlement (Photograph 7). Our curiosity was answered by the local people in the following words: Cactus plant in this place reduces the effect of lightening and thundering to the houses. Although no scientific facts have been found about the lightning strike with cactus, yet, it could have absorbed harmful radiation and helped flush negative energy out of the house. Features (2008) have mentioned that the scientific research by NASA had found that cactus helps to reduce the potential hazards by absorbing the charges from lightning and it also helps to keep the atmosphere moist.

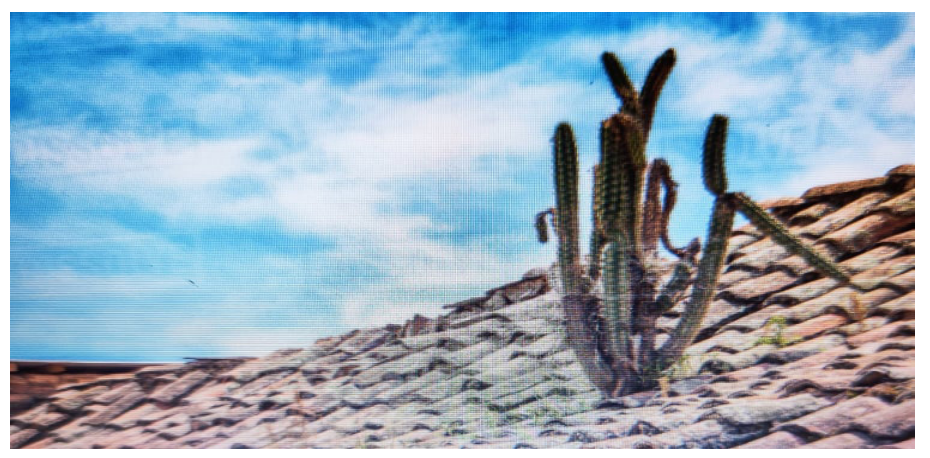

Photograph 7: Planting Siudi (Cactus) on the roof of house

\section{Conclusions}

For generatios people have been practicing traditional indigenous local knowledge and skills that helped for reducing disaster risks on the environment and human beings. Construction of high-rise buildings (Ucho Ghar), preparation of instant bags with 
necessary materials and dam constructions for the purpose of flood control as well as plantation of certain species of plants to mitigate landslides were the common local indigenous knowledge and practices adopted within the flood and landslide prone areas of Kailali district.

Similarly, onset of insects and surprising behavior of domestic animals together with black clouds, daytime storms and hurricanes have been used as the indigenous local knowledge of early warning system for floods, landslides, and heavy rain. Planting cactus on the roof of the house was also observed though not proved scientifically as the indigenous knowledge to reduce the risk of thunderstorm in some parts of the district.

It can be concluded that the available indigenous knowledge and skills on the disaster risk reduction, early warning system and predictions have not been transfered to the younger generations of the area. Therefore, there is an urgent necessary to focus on the policy framework to assimilate indigenous and local knowledge, practices, and skills into the developmental and conservational programs of the area.

\section{References}

Acharya, I. (2012). Indigenous Flood Management Techniques from Gender Perspective: A Case of Kailali District. Administration and Management Review, 24(1), 103-119.

Acharya, S. H. (2017). Action plan 2017-2030 in line with Sendai DRR framework. Kathmandu: Ministry of Home Affairs.

Acharya, S., Subedi, R., \& Shrestha, H. (2016). Need of recognition of traditional institution and use of indigenous knowledge in climate change adaptation: A case-study in Mustang district, Nepal. Nepal Journal of Environmental Science, 4, 53-62. https://doi.org/10.3126/njes.v4i0.22725.

Bhandari, D., Neupane, S., Hayes, P., \& Regmi, B. (2020). Disaster risk reduction and management in Nepal: Delineation of roles and responsibilities. Retrieved from https://www.preventionweb.net/files/72985 delineationofresponsibilityfordisas[1].pdf.

CBS (2011). Population Census of Nepal. Kathmandu: Central Beaureu of Statistics.

Dube, E., Munsaka, E., Dube, E. \&, \& Munsaka, E. (2018). Contribution of indigenous knowledge. Jàmbá Journal of Disaster Risk Studies. 1-8. Retrieved from http:// www.jamba.org.za.

Gautam, D. R. \& Khanal, S. (2009). Case study on indigenous knowledge of disaster risk. Mercy Corps Nepal, (February), 28.pdf. downloded. 9-22-2021.

Lemperiere, F. (2017). Dams and floods. Journal of Engineering. 3(1), 144-149.

Lobovikov, M. (2008). An information bulletin on non- wood forest product. 
Mishra, S. (2009). Country profile of Nepal. An unpublished document on natural hazards in Nepal. pdf. downloded. 9-22-2021.

Mistry, J. (2009). Indigenous Knowledges. International Encyclopedia of Human Geography, 371-376. https://doi.org/10.1016/B978-008044910-4.00101-2.

MOHA. (2013). Integrating disaster risk reduction and climate change adaptation lessons from Hariyo ban.pdf. Nepal disaster report, Kathmandu: Ministry of Home Affairs, Government of Nepal.

MoSTE. (2015), Indigenous and local knowledge and practices for climate resilience in Nepal. Kathmandu: Ministry of Science, Technology and Environment.

Non-Wood News. a1567E.Pdf. (January 2008). pdf. downloded. 9-22-2021. https://doi. org/10.1016/J.ENG.2017.01.018.pdf. downloded. 9-22-2021.

Okonya, J. S., \& Kroschel, J. (2013). Indigenous knowledge of seasonal weather forecasting: A case study in six regions of Uganda. Agricultural Sciences, 04(12), 641-648. https://doi.org/10.4236/as.2013.412086.

Oven, K., Sigdel, S., Rana, S., Wisner, B., Datta, A., Jones, S., \& Densmore, A. (2017). Review of the nine minimum characteristics of a disaster resilient community in Nepal. Durham University: Department of Geography.

Pokhrel, K. P., Chidi, C. L., Timilsena, N. P., \& Mahat, D. K. (2021). Flood hazards and livelihood challenges in lower Karnali river basin: A case from Sudur Paschim. International Journal of Innovative Science and Research Technology.6 (5), May - 2021.

Pokhrel, K. P., Khatiwada, S. P., Paudel, N., Dhakal, K. R. , Chidi, C. L., Timilsena, N. P., \& Mahat, D. K. (2021). Innovative practices for the promotion of local/ indigenous knowledge for disaster risk reduction management in Sudur Paschim Province, Nepal. Journal of Geographical Research, 4(3), 1-11. https://doi. org/10.30564/jgr.v4i3.3223.

Poshan, D., Sharma, J., Marshak, A., \& Stites, E. (2013). Living in the margins : Coping with flood risks and managing livelihoods in Nepal's Far-western Tarai. 1-42. Retrieved from http://fic.tufts.edu/assets/TUFTS 1385 Nepal 2 online-UPDATED.pdf.

Risk Nexus. (2015). Urgent case for recovery: what we can learn from the August 2014 Karnali River floods in Nepal. A report prepared by ISET-Nepal, Practical Action of Nepal and Zurich. (August), 44.

Sakic Trogrlic, R., \& Van Den Homberg, M. (2018). Indigenous knowledge and early warning systems in the Lower Shire Valley in Malawi. UK: Heriot-Watt University, Edinburgh, (January 2020).

Tuladhar, G., Yatabe, R., Dahal, R. K., \& Bhandary, N. P. (2015). Disaster risk reduction knowledge of local people in Nepal. Geoenvironmental Disasters, 2(1). https:// doi.org/10.1186/s40677-014-0011-4

UNEP. (2008). Indigenous Knowledge in Disaster Management in Africa. 1-118. Retrieved from http://africanclimate.net/sites/default/files/Indigenous Booklet UNEP.PDF. 